\title{
Vocabulary Acquisition through Direct and Indirect Learning Strategies
}

\author{
Maki Naeimi ${ }^{1} \&$ Thomas Chow Voon Foo ${ }^{1}$ \\ ${ }^{1}$ School of Languages, Literacies and Translation Universiti Sains Malaysia, Penang, Malaysia \\ Correspondence: Maki Naeimi, School of Languages, Literacies and Translation Universiti Sains Malaysia, \\ Penang, Malaysia, Malaysia. E-mail: makinaeimi@yahoo.com
}

Received: July 21, 2015 Accepted: September 21, 2015 Online Published: September 22, 2015

doi:10.5539/elt.v8n10p142 URL: http://dx.doi.org/10.5539/elt.v8n10p142

\begin{abstract}
Vocabulary learning has long been considered as one of the essential components for developing language learning. However, language learners are required to not just concern about memorizing definitions but also integrating vocabulary meaning into their present knowledge. Many strategies such as direct or indirect ones may be integrated to enhance vocabulary acquisition. Subsequently, the current reserch was an attempt to investigate the effectiveness of implementing direct versus indirect vocabulary learning strategies on vocabulary acquisition of pre-intermediate language learners. To fulfill the aim of the study, sixty students were selected and assigned into two experimental groups (A \& B) based on a vocabulary pre-test. During the study, group A was taught vocabulary through direct strategies (i.e., Structured reviewing, Using mechanical techniques) while group B was taught vocabulary through indirect strategies (i.e., Organizing, Discussing your feelings with someone Else) for developing their vocabulary storage in reading comprehension. At the end of the research, all the participants were given another vocabulary test. The results indicated that the direct group (A) outperformed the indirect group (B). The results showed that direct strategies at pre- intermediate level can lead to higher achievement of vocabulary storage in reading comprehension.
\end{abstract}

Keywords: direct and indirect vocabulary learning strategies, Vocabulary Learning Strategies (VLSs)

\section{Introduction}

Learning of vocabulary as one of the basic communication tools is often considered by language learners as the most difficult field in language learning (Celik \& Toptas, 2010). Many researchers such as Coady and Huckin (1997), Harley (1996) and Richards and Renandya (2002) have considered a good knowledge of vocabulary to be crucial to of communicative competence. Indeed, in order to understand the meaning of different kinds of English sentences and passages, it is important to have excellent and huge vocabulary storage (Rupley et al., 1999). According to Tozcu and Coady (2004), acquiring adequate knowledge of vocabulary is one of the significant issues which enhance reading comprehension.

Vocabulary learning has long been considered as a prerequisite element of reading comprehension (Anderson $\&$ Freebody, 1981). According to Thompson (1999), the successful comprehension of different kinds of texts is the result of the development of students' vocabulary knowledge. However, Nichols and Rupley (2004) highlighted the point that successful language learners should go beyond just memorizing definitions. In effect, they should integrate the meanings of words into their existing knowledge to develop conceptual representations of vocabulary in various contextual situations.

In view of the above, one of the efficient methods to enhance students' vocabulary competence is through the identification of efficient language learning strategies (LLSs) followed by training the learners how to utilize them effectively (Oxford, 1996). With regard to teaching LLSs, Islami-Rasekh and Ranjbari (2003) underscored the point that language learning strategy training enhances learning output and process due to it facilitates students' consciousness of how to learn effectively. Therefore, vocabulary learning strategies as a sub-category of learning strategies in general (Nation, 2001) are important due to the fact learning of vocabulary often poses some difficulties for language learners. According to Gu (1994), specific strategies which are used by non-native 
learners for learning of new vocabularies in the target language are called 'vocabulary learning strategies'. Takač (2008) notes that VLS are particular strategies used for learning vocabulary in any field of language learning.

Among many scholars, Cohen and Macaro (2007) and Farhady (2006) have identified different vocabulary learning strategies such as: 1). memorization strategies, 2) repetition strategies, 3) association strategies, 4) key word method, 5) inferencing strategy, 6) dictionary use, 7) sematic grid strategies, and 8) word lists. As stated by Farhady (2006), applying particular kinds of strategies forms an effort to word attainment that affects the level of second language ability.

Vocabulary learning strategies for vocabulary acquisition enhancement are still being under investigation. In regard to this, Oxford (1990) considers vocabulary learning strategies to be direct and indirect. According to Oxford (1990), direct vocabulary acquisition studies emphasize that vocabulary can be learnt using tools such as dictionaries and vocabulary lists that make the students pay more attention into explicit interaction with the meaning and form of vocabulary. On the other hand, indirect strategies enhance learning indirectly (Oxford, 1990). Indirect learning of vocabulary is defined as a strategy of word learning which arises without the particular intention to emphasis on word.

A small number of papers which will be reviewed in the next part have been manipulated to investigate the usage of vocabulary learning strategies (VLS) in general and by outlining and focusing on direct and indirect vocabulary learning strategies in particular. Generally, it is accepted that students' performance in language learning is considerably influenced by the utilization of vocabulary learning strategies (Sarani \& Kafipour, 2008). However, because there is little of research in such field of study in Iran, the aim of the current research is to paint a preliminary picture of direct and indirect vocabulary learning strategies utilized by the Iranian as a foreign language learners at pre-intermediate level. Thus, the present research is to gauge the influences of two direct (i.e., Structured Reviewing, Using Mechanical Techniques) and two indirect (i.e., Organizing, Discussing your Feelings with Someone Else) vocabulary learning strategies on the Iranian as EFL university students' vocabulary learning.

\section{Literature Review}

The essential role of word in understanding language cannot be denied. According to Stahl (1990), there is a close relationship between proper knowledge of vocabulary and reading comprehension for the purpose of the comprehending the target language. As a matter of fact having adequate knowledge of vocabulary can assist to reading comprehension ability and reading ability can contribute to vocabulary enhancement (Chall, 1987). Moreover, the understanding of approximately each piece of writing in both native and foreign language is not practical without comprehending the passages' main words (Laufer, 1997).

In view of the above, many works (Beck, et al., 1982; McKeown et al., 1983; McKeown et al., 1985; Perfetti, \& Stafura, 2013; Poulsen, \& Elbro, 2013; Zhang et al., 2013 among others) have been managed to identify the relationship between adequate knowledge of vocabulary and reading comprehension ability. Consequently, having the adequate knowledge of vocabulary is a crucial component which affects reading success. In fact, having proper command on vocabulary can enhance comprehension in the process of reading, but such influence was identified only when the teaching program supplies rich experiences with vocabularies (Stahl, 1986; Beck \& McKeown, 1991). However, the results of former studies revealed that vocabulary research will be more effective if students are actively engaged with the vocabularies they are acquiring through the utilization of various strategies (Coomber et al., 1998).

Vocabulary learning strategies have been classified differently by different researchers. For example, Ahmed (1989, cited in Nyikos \& Fan, 2007) classified the 38 strategies his Sudanese students employed into five macro strategies of memorization, dictionary use, practice, note-taking, and group work. Gu and Johnson (1996) developed a 91-item VLS questionnaire dividing it into various parts such as metacognitive regulation, dictionary strategies, guessing strategies, memory strategies (rehearsal and encoding), and finally activation strategies. Gu and Johnson (1996), however, highlight the point that learners utilize a combination of strategies rather than only one in learning vocabulary.

The use of vocabulary learning strategies among university learners of English in Sudan was the focus of a study conducted by Ahmed (cited in Ranalli, 2003). In his study, a structured interview and observation during think-aloud tasks were used and the students were divided into several groups of 'good' students and 'underachievers' based on school records and the subjective evaluations of school officials. The findings of the study were indicative of the fact that strategy use was more evident among learners in the three clusters of 
high-achieving students. The learners of this study were found out the advantages of learning vocabulary in context, were aware of their learning, and consciously recognized the connections between new and previously learned vocabularies. Conversely, students in the two groups who did not make a significant improvement exhibited little use of strategies and revealed little consciousness of the need to engage existing and new knowledge. The results of the study also indicated that note taking strategy was utilized by all the participants. However, there was significant variation in the impressive with which good and underachieving students employed these strategies. This was one of the first studies to consider the relationship between vocabulary learning strategies and success in learning.

Islami-Rasekh and Ranjbari (2003) examined the effect of metacognitive strategy instruction on word acquisition and determined two groups for their study. First group assigned as control group and second one as EFL language learners. The experimental group was at intermediate level of language proficiency. However, the two groups were instructed how to use strategies for enhancement of their vocabulary learning for a period of 10 weeks, only the experimental group taught metacognitive strategy training. The instruction model of study was according to the theoretical framework for language learning strategies training determined by Chamot and O'Malley (1994). The findings of the study revealed that direct metacognitive strategy instruction could significantly improve the vocabulary knowledge of EFL learners.

With the same line, Tassana-ngam (2005) also identified that teaching Thai EFL undergraduate learners how to use vocabulary learning strategies such as semantic context, keyword method, dictionary work, grouping and semantic mapping could enhance the knowledge of vocabulary learning and improve ability of how to acquire vocabulary effectively.

In attempting to present vocabulary-learning-strategy instruction into a foreign language classroom, research informs us to some potential difficulties such as: there may be some resistance to application of those vocabulary learning strategies, which need deeper explanation, due to the cognitive attempt required in memorizing vocabularies in this manner (Nielsen, 2003). Using dictionaries, finding the equivalent translation, synonyms and antonyms, repeating, and memorizing words are the most commonly used vocabulary learning strategies in Iran. The learners forget whatever vocabulary they have learned if they do not practice them for long time. Thus, the learners need a more effective method for acquiring new vocabularies. Moreover, few studies have identified the direct and indirect aspects of vocabulary learning strategies.

To the best knowledge of the present researchers and as far as the related review of literature is concerned, there are no studies which have focused on the effectiveness of direct and indirect vocabulary learning strategies on vocabulary acquisition in an EFL context such as Iran. So with the gap existing in the literature, the present study is aimed at identifying the role of direct (i.e., Structured Reviewing, Using Mechanical Techniques) and indirect (i.e., Organizing, Discussing your Feelings with Someone Else) vocabulary learning strategies on enhancing the Iranian EFL learners' vocabulary acquisition.

\section{Research Questions}

More specifically, the present research will attempt to provide address the following research questions:

1) To what extent does employing direct vocabulary learning strategies improve the Iranian EFL learners' vocabulary acquisition?

2) To what extent does employing indirect vocabulary learning strategies improve the Iranian EFL learners' vocabulary acquisition?

\section{Significance of the Study}

This study would guide the instructors to inform learners about direct and indirect language learning strategies that they use in order to improve their vocabulary acquisition effectively. By focusing on two direct (Structured Reviewing and Using Mechanical Techniques) and two indirect (Organizing and Discussing your Feelings with Someone Else) vocabulary learning strategies training and their effect on word knowledge enhancement of the Iranian EFL undergraduate learners, the present research will perform as a guide for language teachers to either apply direct or indirect vocabulary learning strategies for the better improvement of the language learners' vocabulary acquisition. 


\section{Method}

\subsection{Participants}

The initial population of the current research was 100 English as a Foreign Language (EFL) university students including both males and females aged from 19 to 25 from Islamic Azad University in Iran. Out of the initial population, 60 homogeneous language learners were selected based on the scores which they obtained on a vocabulary pre-test adapted from Objective Placement Test (Lesley et al., 2005).

\subsection{Instruments}

For the purpose to collect data for the current study, two instruments and one material were utilized. The first and the second instruments were 2 parallel vocabulary tests which were used as the pre-posttests. Each test includes 40 multiple-choice vocabulary items. Prior to the main data collection, a pilot study was run to verify that both tests were parallel and reliable.

The material used included 8 units of reading lessons and tasks as the course materials which the researchers prepared to both the direct and indirect groups. These reading lessons and tasks were the same for both groups and were adopted from the Select Readings (Pre-intermediate level) written by Lee and Gunderson (2002).

\subsection{Procedure}

This study was an experimental research based on pre-test and post-test scheme. The first step to take was to assure that the two sample vocabulary tests were parallel. According to Bachman (1990), when two tests measure the same capability and have the same statistical means and variances when administered to the same group with a short interval they are considered as parallel.

In view of the above, both sample vocabulary tests were administered to 20 trial language learners with an interval of 2 days. Then, the means and the variances of both tests were calculated separately. The results of the statistical analysis of the both tests shown in Table 1 indicated that both tests were parallel.

Table 1. Descriptive statistics related to the administration of the two tests to the same group

\begin{tabular}{lllllll}
\hline & $\mathrm{N}$ & Minimum & Maximum & Mean & Std. Deviation & Variance \\
\hline First Test & 20 & 28 & 37 & 33 & 1.325 & 0.69 \\
Second Test & 20 & 33 & 39 & 36 & 1.843 & 0.76 \\
Valid N & 20 & & & & & \\
\hline
\end{tabular}

After it was ascertained that both tests were parallel, the second step was to verify the reliability of the two parallel vocabulary tests. Using the scores received from the manipulating of both vocabulary tests in the first step of instruments verification process, the researchers employed parallel tests method to verify the reliability of the two sample parallel vocabulary tests. The findings of the data analysis of the reliability coefficients of the two parallel tests shown in Table 2 showed that both tests were reliable.

Table 2. Reliability Statistics related to the two parallel tests

\begin{tabular}{lll}
\hline Common Variance & 0.73 \\
\hline True Variance & 0.52 & \\
Error Variance & 0.03 & \\
Common Inter-Item Correlation & 0.75 & $\mathrm{~N}=20$ \\
Reliability of Test 1 (Cronbach's Alpha) & 0.79 & $\mathrm{~N}=20$ \\
Reliability of Test 2 (Cronbach's Alpha) & 0.84 & \\
\hline
\end{tabular}


After verifying both tests to be parallel and reliable, one of them was administered to 100 Iranian EFL students. Then 60 learners whose scores were one standard deviation above or below the mean were selected as pre-intermediate homogeneous participants. Following, the 60 selected language learners were divided into two groups of equal number namely group $\mathrm{A}(\mathrm{n}=30)$ and group $\mathrm{B}(\mathrm{n}=30)$ vocabulary learning strategies. During the study which lasted for 10 academic sessions, both groups were run by one of the researchers utilizing direct or indirect strategies. In other words, the group A was trained vocabulary through direct strategies (i.e., Structured Reviewing, Using Mechanical Techniques) while group B was taught vocabulary by indirect strategies (i.e., Organizing, Discussing your Feeling with Someone Else). The following sections briefly introduce the two particular strategies which were implemented in each class (Structural Reviewing and Using Mechanical Techniques as direct strategies and Organizing and Discussing your Feelings with Someone Else as indirect strategies) during the period of the study in order to enhance vocabulary acquisition. The point should be highlighted that during the first session, the direct and indirect strategies were introduced to the participants in both groups. Following the first session, from session two to nine, the eight reading passages were taught to both groups with different strategies which are explained below. The post-test was given to all the participants in the last session (10th).

\section{Direct Strategy}

\subsection{Structure Reviewing}

According to Oxford (1990), one way of remembering and using new vocabulary in the target language using the Structured Reviewing as an effective technique. This strategy included reviewing materials at different intervals. For example, acquiring a collection of vocabulary item in English, then learners follow 15 minutes before applying them again, and practiced them an hour later, three hours later, the next day, two days later, four days later, the following week, and so on until the materials became more or less were automatic. The students were suggested recommended to put the vocabulary into a context or recombining them to make new sentences.

\subsection{Using Mechanical Techniques}

Based on Oxford (1990), in order to remember what has been learned, using the Mechanical Technique was applied as an impressive strategy in using flashcards with the new vocabulary written on one side and the definition written on the other. To use a new vocabulary in context and get writing practice, students wrote the new expression in a full sentence on flash cards. Flashcards were moved from one pile to another pile in the classroom depending on how well the students knew them. According to Oxford (1990) suggestions, the researchers required learners to read and practice the vocabularies when they had some free time. For example, they were required to read them on the bus, in lines, etc.

\section{Indirect Strategy}

\subsection{Organizing}

Applying this type of indirect strategy requires different tools, such as planning well, preparing the best possible environment for study, and keeping a language learning notebook. Based on this strategy, the students had the good physical environment as a significant factor for every language skill. It supplied the students with enough input in a convenient, peaceful circumference without too much background noise which assisted establish a good classroom setting and motivated the learners to create an convenient environment for learning at home. On the other hand, it helped them in improving practical weekly plans for language learning, with plenty of time allocated to outside the classroom practice in the language skills. Consequently, a language learning notebook was also used as an excellent organizational aid for students. The notebook was usefully utilized a number of activates such as class assignments, writing down the new target language expressions, purposes and objects, strategies which were more effective, things to remember, and organized it for the best use (Oxford, 1990).

\subsection{Discussing Your Feelings with Someone Else}

Since learning another language is effortful and language learners most of the times need to negotiate this process with other people (Oxford, 1990). Thus, language learners like to discuss their daily events with other people. In this indirect strategy, learners use diaries to comprehend and kept track of their thoughts, attitudes, and strategies for learning more vocabularies. If learners felt at ease enough, they shared their diary entries during group discussion by dividing learners in several groups in class once or twice a week. Discussions of feelings 
could also take place outside the classroom setting with peers or a family member (Oxford, 1990).

\section{Results and Discussion}

To provide answers to the research questions, the data obtained from the implementation of the pre-post-tests to group one (group A) and group two (group B) were compared separately using the statistical analysis of a paired sample t-tests (Tables 3 and 4).

Table 3. Descriptive statistics related to group A (direct strategies) pre-posttests findings

\begin{tabular}{lllll}
\hline Group & $N$ & MEAN & $S D$ & $t$-test \\
\hline Group A pretest & 30 & 31 & 0.54 & -3.645 \\
Group A posttest & 30 & 36 & 0.65 & $P=0.02$ \\
\hline
\end{tabular}

T-observed $=-3.645 \quad$ T-critical $=1.729 \quad$ T-observed is bigger than $\mathrm{t}$-critical.

Table 4. Descriptive statistics related to group B (indirect strategies) pre-post-tests findings

\begin{tabular}{lllll}
\hline Groups & $N$ & MEAN & $S D$ & $t$-test \\
\hline Group B pretest & 30 & 30 & 0.53 & 0.043 \\
Group B posttest & 30 & 32 & 0.49 & $P=0.782$ \\
\hline
\end{tabular}

T-observed $=-0.043 \quad$ T-critical $=1.729 \quad$ T-observed is smaller than $\mathrm{t}$-critical.

Concerning the group A accomplishment in the pre-post-tests, it can be comprehend that the mean score of the learners in this group in the pre-test was 31 out of 40 . This mean score improved to 36 in the post-test which is indicative of the fact that a significant progress was made in their accomplishment. An inspection of the two means suggest that the mean for post-test was significantly greater than the mean of the pre-test. The magnitude of the differences in the means was large $\left(\eta^{2}=0.11\right)$. Compared to this eta-squared value obtained $\left(\eta^{2}=0.021\right)$ to Cohen $(1988)$ criteria $(0.01=$ small effect, $0.06=$ moderate effect, and $0.14=$ large effect $)$, this is clear that the effect size found is a large effect size. A large effect size suggests that the mean difference of the pre-posttests scores of group A is very big or large. This shows that using direct vocabulary learning strategies could improve vocabulary learning of learners in this group. The findings of the paired sample t-test for the data obtained from the pre-posttests of group A (Table 1) also indicated that the improvement was statistically significant $(\mathrm{p}<0.05)$.

In relation to the findings of data analysis obtained from the pre-post tests for group $\mathrm{B}$, the mean score in the pre-test was 30 out of 40 and in the post-test was 32 out of 40 . This minor progress can be interpreted as enhancement. However, an examination of the two means suggest that the mean for post-test was slightly higher than the mean of the pre-test. The magnitude of the differences in the means was large $\left(\eta^{2}=0.03\right)$. Comparing this eta-squared value obtained $\left(\eta^{2}=0.03\right)$ to Cohen criteria $(0.01=$ small effect, $0.06=$ moderate effect, and $0.14=$ large effect), it is obvious that the effect size obtained is a moderate effect size. A moderate effect size suggests that the mean difference of the pre-post-tests scores of group B is not very big or large. This implies that using indirect vocabulary learning strategies could not improve vocabulary learning of the students in group B. The results of the paired sample t-test for the data received from group B also indicated that the improvement was not statistically significant ( $\mathrm{p}>0.05)$.

The results of the present research is in line with previous studies (e.g. Waring, 1995; Laufer \& Shmueli, 1997; Qian, 1996, Beck et al., 2002; Beck et al., 2005; Beck et al., 2007; Stahl \&Fairbanks, 1986) which highlighted the pedagogical value of using direct vocabulary learning strategies in language learning classrooms.

One of the reasons that the participants who were instructed by direct strategies performed better than the participants who were instructed by indirect strategies might be that at the early stages of language learning, language learners need a basic vocabulary before they can even start to learn from context as they have insufficient knowledge and the text is also too dense with unknown vocabularies (Waring, 1995, p. 2). Indeed, it guessing the meaning of the vocabulary from context as an indirect strategy be left to a later stage when the learners have enough knowledge (Waring, 1995). 
By using direct instructing strategies for acquiring vocabulary, the instructor directly introduces the vocabulary and supplies the definitions of vocabulary directly. According to the researcher's observation, the direct strategies such as Structured Reviewing were easy to use and to conduct with only some help from the teacher (one of the researchers). With regard to the Mechanical Techniques, the researcher asked the students to prepare flash cards and use them constantly during the treatment. This strategy was very popular among students and they liked and utilized it more than others due to the fact that it is easy to utilize and assisted them for improving their vocabulary storage in their reading comprehension. Based on the observations of the researcher during the treatment, the students faced no difficulty in applying and using direct strategies. Mechanical techniques strategy which was used more by the participants in Group A. This might be because the students understood that this strategy is a very easy and effective way for developing their vocabulary and can assist them to understand the meaning of new vocabularies in different reading comprehension texts.

In contrast to the participants in group A, the participants in group B who were instructed by indirect strategies could not significantly improve their vocabulary acquisition. According to the observations of the researcher, they requested more assistant from the teacher in order to understand how to use the indirect strategies. This might have influenced their learning the new vocabularies. According to the observation of researcher, the students could not organize the subjects for learning the necessary vocabulary. This may be because of their level of language proficiency for Organizing or Discussing their Feelings with Someone Else. According to Schmitt and McCarthy (1997), the proficiency of learners might actually enhance development in indirect strategy use.

Implementing indirect strategies requires the teachers to provide the language learners with more assistance. Utilizing indirect strategies also require more discussion from the language learners. According to Oxford (1990), Discussing your Feeling with Someone Else strategy needs the effort from the students to speak and negotiate their daily events, their thoughts, and attitudes with each other. However, in the case of the present research, the participants in group B did not participate so much in class discussions.

\section{Conclusion}

The crucial aim of the current study was to gauge the effectiveness of two direct (i.e., Structured Reviewing, Using Mechanical Techniques) and two indirect (i.e., Organizing, Discussing your Feelings with Someone Else) vocabulary learning strategies designed to assist language learners to improve their vocabulary storage in reading comprehension skill.

The findings of this study were indicative of the fact that the selected direct vocabulary learning strategies (i.e., Structured Reviewing, Using Mechanical Techniques) compared with the indirect strategies had a significant effect on vocabulary acquisition of the language learners. The obtained results support using direct vocabulary learning strategies. Based on the findings of the present research, implementing direct vocabulary learning strategies particularly at pre- intermediate level can enhance vocabulary strategies.

Consequently, teachers are encouraged to implement direct vocabulary strategies because of their easy and effective application particularly at the early stages of vocabulary learning. In the same line, curriculum developers and material producers are also recommended to produce language learning materials based on strategy-instruction especially on direct and indirect strategies that teachers can use throughout their class research. Indeed, the materials should be congruent with the students' learning strategies and they should be appealing to students' needs and interests. It is suggested that material designers may develop teaching materials.

Finally, the point should be underscored that the present research had some limitations which can be the focus of future research. Firstly, the participants of the present research were pre-intermediate language learners. Different results might be produced if the study is conducted with low or advanced levels language learners. Secondly, only two direct and two indirect vocabulary learning strategies were implemented to find out the effectiveness of utilizing direct and indirect vocabulary learning strategies on vocabulary acquisition. Indeed, conducting further research which focus on the effect of using more/other direct/indirect vocabulary learning strategies on vocabulary acquisition is warranted. Finally, because of the short duration of the research, cautions should be made about considering the better performance of the participants in one group as an indication of vocabulary acquisition. In other words, other factors might have affected the results.

\section{Acknowledgements}

The authors would like to acknowledge School of Languages, Literacies and Translation Universiti Sains, Malaysia, 11800, Penang, Malaysia for funding the research project. 


\section{References}

Anderson, R. C., \& Freebody, P. (1981). Vocabulary knowledge. In J. Guthrie (Ed.), Comprehension and teaching: Research reviews (pp. 77-117). Newark, DE: International Reading Association.

Bachman, L. F. (1990). Fundamental considerations in language testing. Oxford University press, Oxford, London.

Beck, I. L., \& McKeown, M. G. (2007). Different ways for different goals, but keep your eye on the higher verbal goals. In R. K. Wagner, A. E. Muse, \& K. R. Tannenbaum (Eds.), Vocabulary acquisition: Implications for reading comprehension (pp. 182-204). New York: Guilford.

Beck, I. L., McKeown, M. G., \& Kucan, L. (2002). Bringing words to life: Robust vocabulary instruction. New York: Guilford.

Beck, I. L., McKeown, M. G., \& Kucan, L. (2005). Choosing words to teach. In E. H. Hiebert \& M. L. Kamil (Eds.), Teaching and learning: Bringing research to practice (pp. 207-242). Mahwah, NJ: Lawrence Erlbaum.

Beck, I. L., Perfetti, C. A., \& McKeown, M. G. (1982). The effects of long-term vocabulary instruction on lexical access and reading comprehension. Journal of Educational Psychology, 74, 506-521. http://dx.doi.org/10.1037/0022-0663.74.4.506

Beck, I., \& McKeown, M. (1991). Conditions of vocabulary acquisition. In R. Barr, M. L. Kamil, P. Mosenthal, \& P. D. Pearson (Eds.), Handbook of reading Research (Vol. 2, pp. 789-814). New York: Longman.

Celik, S., \& Toptas, V. (2010). Vocabulary learning strategies of Turkish EFL learners. Procedia - Social and Behavioral Sciences, 3, 62-71. http://dx.doi.org/10.1016/j.sbspro.2010.07.013

Chall, J. S. (1987). Two vocabularies for reading: recognition and meaning. In McKeown, M., \& Curtis, M. (Eds.), The Nature of Vocabulary Acquisition. Lawrence Erlbaum Association, New Jersey (pp. 7-17).

Chamot, A. U., \& O'Malley, J. M. (1994). Language learner and learning strategies. In N. C. Ellis (Ed.), Implicit and explicit learning of languages (pp. 371-392). London: Academic.

Coady, J., \& Huckin, T. (1997). Second language vocabulary acquisition. Cambridge: Cambridge University Press.

Cohen, J. (1988). Statistical power analysis for the behavioral sciences ( $2^{\text {nd }}$ Ed.). Hillsdale, NJ: Erlbaum.

Cohen, C., \& Macaro, E. (2007). Language learner strategies. Oxford: Oxford University Press.

Coomber, J. E., Peet, H. D., \& Smith, C. B. (1998). Teaching Vocabulary. Fargo, ND: Division of Continuing Education, North Dakota State University.

Farhady, H. (2006). Twenty-five years of living with applied linguistics: Collection of articles. Iran, Tehran. Rahnama press.

Gu, P. Y. (1994). Vocabulary Learning Strategies of Good and Poor Chinese EFL Learners. The Twenty-Eighth Annual Convention and Exposition (p. 27). Baltimore.

Gu, Y., \& Johnson, R. K. (1996).Vocabulary learning strategies and language learning outcomes. Language Learning, 46(4), 643-679. http://dx.doi.org/10.1111/j.1467-1770.1996.tb01355.x

Harley, B. (1996). Vocabulary learning and teaching in a second language. Canadian Modern Language Review, 53, 3-12.

Islami-Rasekh, Z., \& Ranjbari, R. (2003). Metacognitive strategy training for vocabulary learning. TESL-EJ, $7(2), 1-15$.

Lee, L., \& Gunderson, E. (2002). Select Readings-Pre-Intermediate. Oxford University Press.

Laufer, B. (1997).Thelexicalplightinsecondlanguagereading. InJ., Coady, \& T. Huckin, (Eds.), Second Language Vocabulary Acquisition (pp. 20-34). Cambridge UniversityPress, Cambridge.

Laufer, B., \& Shmueli, K. (1997). Memorizing new words: Does teaching haveanything to do with it? RELC JOURNAL, 28(1), 89-106. http://dx.doi.org/10.1177/003368829702800106

Lesley, T., Hanson, C., \& Zukowski- Faust, J. (2005). Interchange/ Passage Placement and Evaluation Package. 
Cambridge: Cambridge University Press.

McKeown, M. G., Beck, I. T., Omanson, R. C., \& Perfetti, C. A. (1983). The effects of long-term vocabulary instruction on reading comprehension: A replication. Journal of Reading Behavior, 15, 3-18. http://dx.doi.org/10.1080/10862968309547474

McKeown, M. G., Beck, I. L., Omanson, R. C., \& Pople, M. T. (1985). Some effects of the nature and frequency of vocabulary instruction on the knowledge and use of words. Reading Research Quarterly, 20, 522-535. http://dx.doi.org/10.2307/747940

Nation, I. S. P. (2001). Learning vocabulary in another language. Cambridge: Cambridge University Press. http://dx.doi.org/10.1017/CBO9781139524759

Nichols W. D., \& Rupley, W. H. (2004). Matching instructional elesign with vocabuIIC lar; instruction. Reading Horizons, 45(1), 55-71.

Nielsen, B. (2003). A review of research into vocabulary learning and acquisition. Retrieved July 19, 2006, from http://www.kushiro-ct.ac.jp/library/kiyo/kiyo36/Brian.pdf

Nyikos, M., \& Fan, M. (2007). A review of vocabulary leaning strategies: Focus on language proficiency and learner voice. In A, D, Cohen, \& E. Macaro (Eds.). Language Learner Strategies (pp. 251-274), Oxford: Oxford University Press.

Oxford, R. (1990). Language learning strategies: What every teacher should know. Boston: Heinle and Heinle.

Oxford, R. L. (Ed.). (1996). Language learning strategies around the world: Cross- cultural perspectives (Technical Report 13). Honolulu: University of Hawai ${ }^{i} i$, Second Language Teaching \& Curriculum Center.

Perfetti, C., \& Stafura, J. (2013). Word knowledge in a theory of reading comprehension. Scientific Studies of Reading, (ahead-of-print), 1-16.

Poulsen, M., \&Elbro, C. (2013). What's in a Name Depends on the Type of Name: The Relationships Between Semantic and Phonological Access, Reading Fluency, and Reading Comprehension. Scientific Studies of Reading, 17(4), 303-314. http://dx.doi.org/10.1080/10888438.2012.692743

Qian, D. D. (1996). ESL vocabulary acquisition: Contextualization and decontextualization. The Canadian Modern Language Review, 53(1), 120-142.

Ranalli, J. M. (2003). The treatment of key vocabulary learning strategies in current ELT course books: Repetition, resource use, recording. United Kingdom: University of Birmingham.

Richards J. C., \& Renandya, W. A. (2002) Methodology in language teaching: An anthology of current practice. Cambridge: Cambridge University Press. http://dx.doi.org/10.1017/CBO9780511667190

Rupley, W. H., Logan, J. W., \& Nichols, W. D. (1999). Vocabulary instruction in a balanced reading program. The Reading Teacher, 52(4), 336-346.

Sarani, A., \& Kafipour, R. (2008). The study of language learning strategies use by Turkish and Kurdish EFL university students. Language Forum, 34(2), 173-188.

Schmitt, N., \& McCarthy, M. (1997). Editors' comments - acquisition section. In N. Schmitt, \& M. McCarthy (Eds.), Vocabulary: description, acquisition and pedagogy (pp. 228-236). Cambridge: Cambridge University Press.

Stahl, S. A. (1986). Three principles of effective vocabulary instruction. Journal of Reading, 29, 662-668.

Stahl, S. A. (1990). Beyond the Instrumental Hypothesis: Some Relationships between Word Meanings and Comprehension. Technical report no. 505 of the Center for the Study of Reading. University of Illinois at Urbana-Champaign.

Stahl, S. A., \& Fairbanks, M. M. (1986). The effects of vocabulary instruction: A model-based metaanalysis. Review of Educational Research, 56, 72-110. http://dx.doi.org/10.3102/00346543056001072

Takač, V. P. (2008). Vocabulary learning strategies and second language acquisition. Clevedon, UK: Multilingual Matters.

Tassana-ngam, I. (2005). The effect of vocabulary learning strategies training on Thai University students' word 
retention in the second language classroom. DAI-C, 66(2), 263.

Thompson, R. A. (999). B Iancmg vocabulary instruction with teacher-directed and student-centered actiVItIes. In S. Blair-Larson \& K. Williams (Eds.), The balanced reading program (pp. 24-36). Newark DE: International Reading Association.

Tozcu, A., \& J. Coady. (2004). Successful Learning of Frequent Vocabulary through CALL also Benefits Reading Comprehension and Speed. Computer Assisted Language Learning, 17 (5), 473-495. http://dx.doi.org/10.1080/0958822042000319674

Waring, R. (1995). Second language vocabulary acquisition: Linguistic context and vocabulary task design Retrieved June 9, 2012 from http: www1. harenet.ne.ip/ waring/papers/BC.html

Zhang, Y., Tardif, T., Shu, H., Li, H., Liu, H., McBride-Chang, C., ... Zhang, Z. (2013). Phonological skills and vocabulary knowledge mediate socioeconomic status effects in predicting reading outcomes for Chinese children. Developmental psychology, 49(4), 665. http://dx.doi.org/10.1037/a0028612

\section{Copyrights}

Copyright for this article is retained by the author(s), with first publication rights granted to the journal.

This is an open-access article distributed under the terms and conditions of the Creative Commons Attribution license (http://creativecommons.org/licenses/by/3.0/). 